\title{
Estimation of suspended sediment concentration in rivers using acoustic methods
}

\author{
Şebnem Elçi • Ramazan Aydın • Paul A. Work
}

Received: 27 March 2007 / Accepted: 5 November 2008 / Published online: 6 December 2008

(C) Springer Science + Business Media B.V. 2008

\begin{abstract}
Acoustic Doppler current meters (ADV, ADCP, and ADP) are widely used in water systems to measure flow velocities and velocity profiles. Although these meters are designed for flow velocity measurements, they can also provide information defining the quantity of particulate matter in the water, after appropriate calibration. When an acoustic instrument is calibrated for a water system, no additional sensor is needed to measure suspended sediment concentration (SSC). This provides the simultaneous measurements of velocity and concentration required for most sediment transport studies. The performance of acoustic Doppler current meters for measuring SSC was investigated in different studies where signal-to-noise ratio (SNR) and suspended sediment concentration were related using different formulations. However, these studies were each limited to a single study site
\end{abstract}

Ş. Elçi $(\varangle)$ · R. Aydın

Department of Civil Engineering,

Izmir Institute of Technology, Izmir, Turkey

e-mail: sebnemelci@iyte.edu.tr

\section{P. A. Work}

School of Civil and Environmental Engineering,

Georgia Institute of Technology,

Savannah, GA, USA where neither the effect of particle size nor the effect of temperature was investigated. In this study, different parameters that affect the performance of an ADV for the prediction of SSC are investigated. In order to investigate the reliability of an ADV for SSC measurements in different environments, flow and SSC measurements were made in different streams located in the Aegean region of Turkey having different soil types. Soil samples were collected from all measuring stations and particle size analysis was conducted by mechanical means. Multivariate analysis was utilized to investigate the effect of soil type and water temperature on the measurements. Statistical analysis indicates that SNR readings obtained from the ADV are affected by water temperature and particle size distribution of the soil, as expected, and a prediction model is presented relating SNR readings to SSC measurements where both water temperature and sediment characteristics type are incorporated into the model. The coefficients of the suggested model were obtained using the multivariate analysis. Effect of high turbidity conditions on ADV performance was also investigated during and after rain events.

Keywords Acoustic Doppler - Suspended sediment concentration $\cdot$ Streams and rivers • Aegean $\cdot$ Particle size $\cdot$ Multivariate analysis 


\section{Introduction}

A wide variety of techniques have been used to measure flow velocity and sediment concentration in rivers. Acoustic Doppler current meters transmit focused pulses of sound, with known frequency, into the water, and the observed Doppler shift in the sound that is reflected back from suspended particles in the water is used to compute water velocities. The assumption is made that the particles reflecting the sound move at the same speed as the water (Sontek 1998).

Two fundamentally different instrument designs have emerged over the past 20 years. One design provides data defining velocities within a small $\left(O\left(1 \mathrm{~cm}^{3}\right)\right)$ sampling volume, typically $5-10 \mathrm{~cm}$ remote to the instrument head. The other design is typically deployed either on the top or bottom of the water body of interest, and uses range-gating of the reflected sound signal to resolve vertical variations in the velocity profile.

Most acoustic instruments for measurement of flow velocities include measurement of water temperature, since this is an easily measured scalar quantity and influences the speed of sound through the water, which must be known for accurate range-gating of the reflected signal used to compute velocities. The characteristics of the backscattered signal have also been used to infer information about the concentration of material suspended in the water. Acoustic Doppler velocimeters (ADVs) of either design thus have the potential to simultaneously measure velocity, temperature, and suspended sediment concentration with a single instrument, in a minimally intrusive way, since they feature sampling volumes that are remote to the instrument. Moreover, instruments capable of resolving profiles can collect flow velocity and sediment concentration time series data over the whole water column (Elci 2008). They can also be used to measure directional spectra of waves on the water surface (e.g., Work 2008).

An ADV can measure three-dimensional flow velocity at any depth within the water column. The magnitude of the acoustic reflection (signal strength) from the water is a function of the instrument used (influenced by sound frequency, transmit power, receive sensitivity, and range to the measurement volume) and the conditions of the water, primarily the size and concentration of particulate matter.

Conventional methods for collection of suspended sediment concentration data are labor intensive and often have large uncertainty due to spatial and temporal variability of suspended sediment concentration in the water column. Using acoustic instruments for suspended sediment concentration (SSC) measurements in shallow waters has many advantages. After an acoustic instrument is calibrated for a water system, no additional sensor is needed to measure SSC, and simultaneous measurements of velocity and concentration required for most sediment transport studies are provided with a single instrument. Also, turbidity measuring instruments, widely used to indicate the amount of suspended sediment concentration in the water column after being calibrated, use optical methods and have limitations associated with biological fouling. Acoustic sensors are also subject to biofouling, but display much less sensitivity as growth proceeds. In spite of the advantages, the primary barrier to the development of a comprehensive sediment concentration prediction methodology by acoustic methods has been the lack of sufficient coupled observations of suspended sediment concentration and acoustic Doppler velocity measurements.

Several researchers investigated the performance of ADVs for prediction of SSC. Formulations were derived by relating SNR (signal-to-noise ratio) and SSC of the water (Kostaschuk et al. 2004; Alvarez and Jones 2002; Gartner 2002; Hosseini et al. 2005; Creed et al. 2001; Rennie et al. 2002). However, these studies were site-specific (limited to a single river or water body) and they did not consider the effect of particle size distribution or water temperature. In a recent study, Hoitink and Hoekstra (2005) investigated the performance of a 1.2 MHz ADCP (acoustic Doppler current profiler) for SSC measurements in a tropical bay, with sediments composed of a mixture of silt and clay. They related simultaneous measurements of velocity and optical backscatter and presented an equation relating particle size and sediment concentration. However, the combined effect 
of water temperature and particle size on the performance of the ADV for SSC was not investigated.

One of the limitations of using an ADV for SSC predictions is that an ADV measures the velocity of acoustic targets (e.g., solid particles) rather than the fluid velocity. As noted above, the sediment and fluid are assumed to travel at the same velocity. This assumption is likely to be valid only when considering fine sediments, dominantly in suspension. For coarser particles (e.g., sand) this effect may introduce additional uncertainty in the velocity measurements. Another limitation is that as the sediment concentration increases, acoustic waves are absorbed in sediment-laden flow and attenuated to the point where the ADV cannot operate properly in high sediment concentrations (i.e., above $200 \mathrm{mg} / \mathrm{l}$ ).

The main goal of the study described here is to improve the methodology for predicting SSC using ADV backscatter data in a quasi-steady scenario as found in a river or stream. The effects of water temperature and particle size distribution on predictive capability were investigated through measurements conducted in different streams in low flow and flood conditions. SSCs were predicted from SNR output from a handheld ADV by applying the sonar equation for sound scattering from fine particles (Sontek 1998). The acoustic signal strength is inversely proportional to the range $(R)$ from the transducers, but also depends on the absorption coefficient of water. Thus, the signal strength is a function of sediment size and size distribution, range to measurement volume, salinity, sound frequency and temperature. Carbo and Molero (2000) showed that the absorption coefficient for sound in water decreases as water temperature increases. Once the ADV is calibrated against a separate SSC measuring device, the changes in SNR can be related to SSC values. In this case, signal strength measurements reported by an ADV were compared to SSC estimates reported by a water quality meter.

A new equation was derived relating SSC to SNR, dimensionless mean sediment diameter, coefficient of gradation of particle size distribution, and water temperature dependent dimensionless absorption coefficient. The coefficients of the pro- posed equation were obtained using multivariate analysis.

\section{Instrumentation}

Measurements of SSC by a water quality meter and flow velocities by ADV were made simultaneously in each of seven different streams. The water quality meter used here measures turbidity by using the scattered light measurement method. Turbidity measurements provide a reading of the amount of scattered light. Turbidity is expressed in terms of the optical property causing the light beam passing through the sample of the fluid to be scattered and absorbed rather than transmitted through the sample. In this study, turbidity measurements were made using DKK-TOA's multi parameter water quality meter. The data accuracy for turbidity was $\pm 3 \%$. The relationship between the suspended solids in the liquid and the light intensity due to particle scatter is determined by the factory calibration of the instrument (1 NTU of turbidity corresponds to $1 \mathrm{mg} / \mathrm{L}$ of SSC). In the laboratory, the relationship between SSC and turbidity was tested and a linear relationship was found.

A Sontek Flowtracker (10 MHz) ADV system was used in this study. The rated accuracy of the ADV velocity measurements is $1 \%$ of current speed (Sontek 1998). A 20-s averaging interval was applied to data with a sample interval of $1 \mathrm{~s}$.

\section{Measurement sites}

Data were collected in the Aegean Region of Turkey (Fig. 1). This region has fertile soils and a typical Mediterranean climate with mild, soft, verdant spring seasons, hot summers, sunny autumns, and warm winters. The Aegean Region features mountain chains oriented perpendicularly to the coast, with numerous valleys between the mountains, permitting the coastal climate to reach inner parts of the region, although some of the provinces inland have characteristics of Continental climate. The broad, cultivated valley 
Fig. 1 Measurement sites

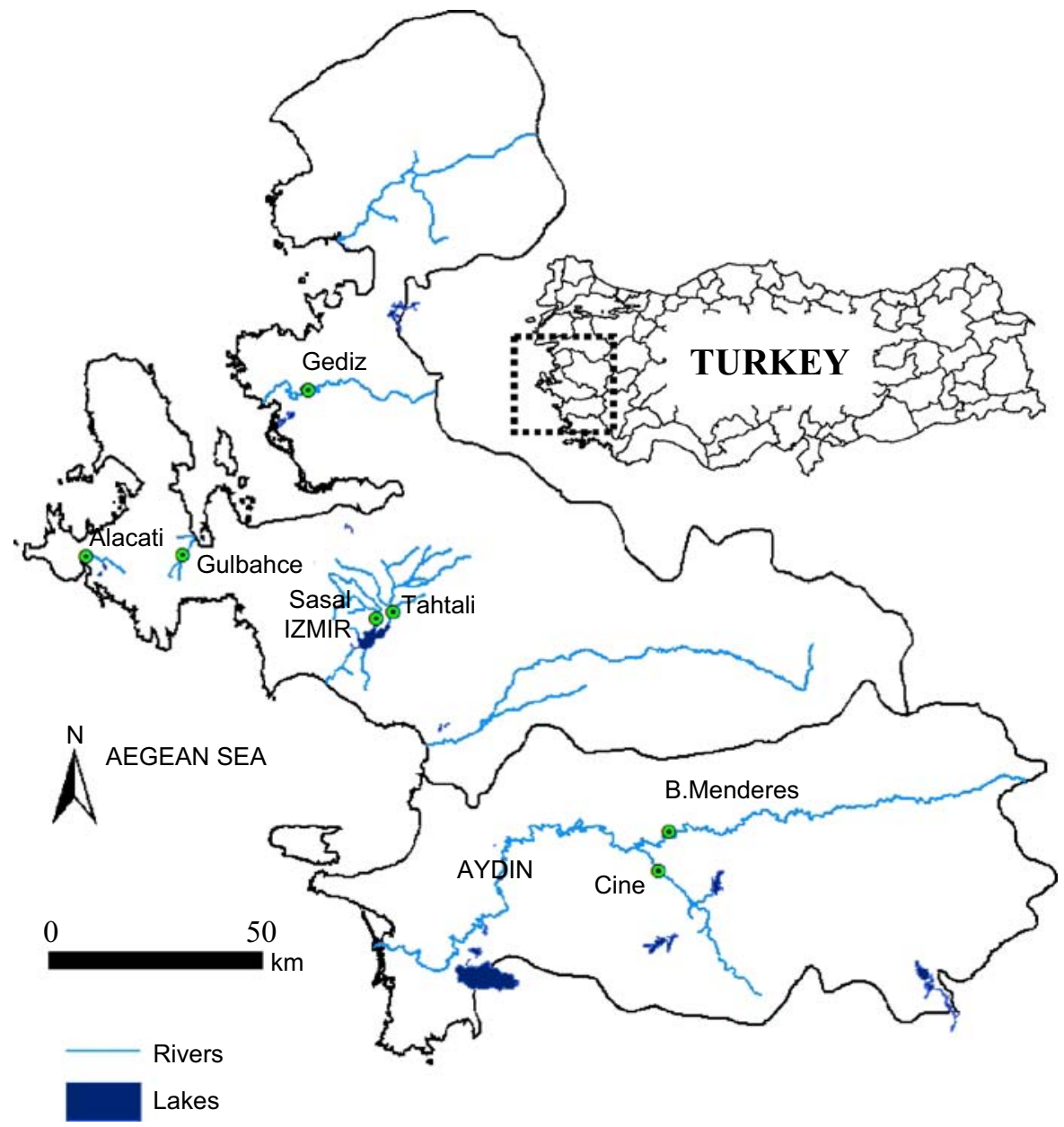

lowlands contain about half of the country's richest farmland, the country's third largest city and a major manufacturing center. The K. Menderes, B. Menderes, and Gediz rivers in the Aegean basin lend their names to the plains through which they flow.

Observations were conducted in the Gediz and B. Menderes Rivers and the Tahtali, Sasal, Alacati, Gulbahce, and Cine streams in the Aegean region (Figs. 1 and 2). The Gulbahce stream is ephemeral, typically dry in summer, whereas the others are perennial but feature large variations in discharge during the year.

The Tahtali and Sasal streams are nourished by water sources in the mountains and precipitation and have very low flowrates during sum- mer because of evaporation and withdrawals for irrigation.

The B. Menderes River is the largest river of the Aegean region with a discharge of approximately $10,000 \mathrm{hm}^{3} /$ year. The Cine stream is the largest tributary of the B. Menderes River. Unfortunately, the B. Menderes River has been polluted for the last 10 years. Pesticides used in agriculture and uncontrolled wastewater discharge from factories are the main reason of the river pollution.

The Gediz River is a very important water resource for the agriculture of the region. The river irrigates very fertile plains near Izmir and Manisa. The Gediz River is also currently considered highly polluted, due to uncontrolled 


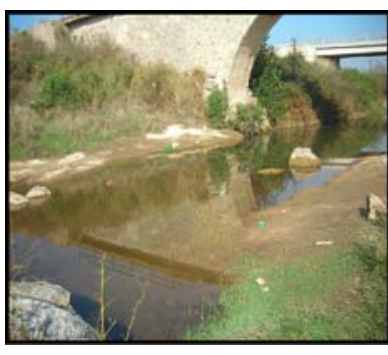

(a) Sasal River

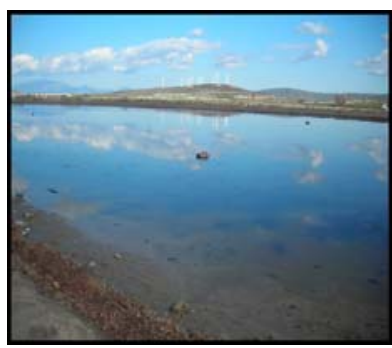

(e) Alacati Stream

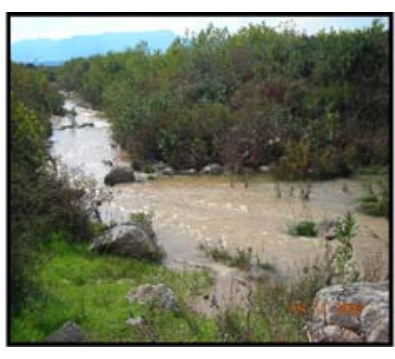

(b) Sasal River (Flood)

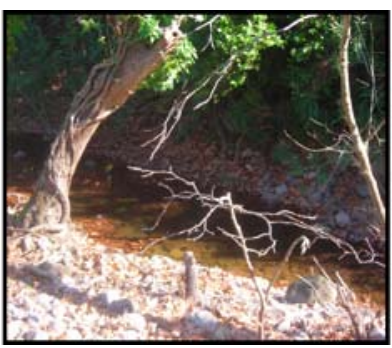

(f) Gulbahce Stream

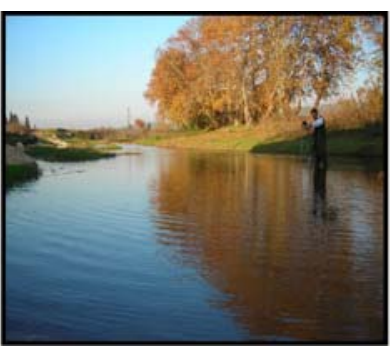

(c) Tahtali River

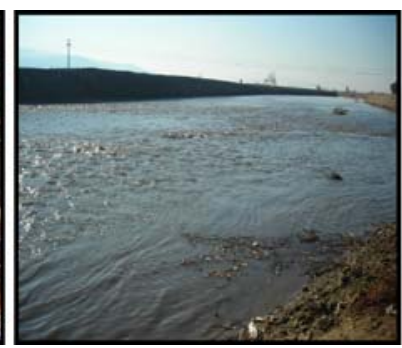

(g) B.Menderes River

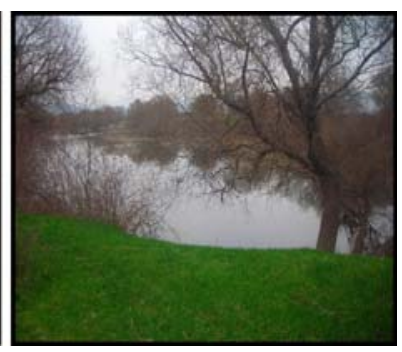

(d) Gediz River

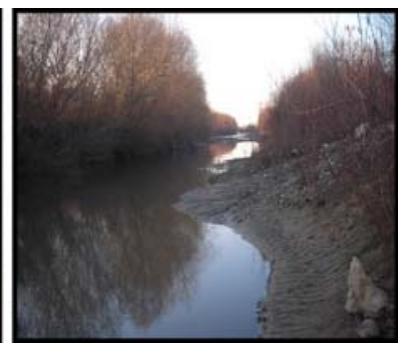

(h) Cine Stream

Fig. 2 Views from streams and rivers where measurements were conducted

discharges from factories and sewage systems nearby.

\section{Methodology}

Simultaneous measurements were made using the turbidity sensor and the Flowtracker ADV at each river site, where SNR data were averaged over $20 \mathrm{~s}$. Measured SNR and SSC data were subjected to statistical analysis to investigate the correlation of the SNR and SSC data.

The Sonar Equation (Eq. 1 below), describes how an acoustic instrument's specific variables affect signal strength data (Sontek 1998).

$$
\begin{aligned}
\mathrm{EL}= & \mathrm{SL}+10 \times \log (\mathrm{PL})-20 \times \log (R) \\
& -2 \times \alpha \times R+\mathrm{Sv}+\mathrm{RS}
\end{aligned}
$$

where, EL = "Echo Level" is the signal strength as measured by the instrument; SL $=$ "Source Level" is a measure of transmitted acoustic power; $\mathrm{PL}=$ "Pulse Length" is the length of the acoustic pulse; $R=$ Range between the transducer and the measurement volume; $\alpha=$ Sound absorption coefficient $(\mathrm{dB} / \mathrm{m}) ; \mathrm{Sv}=$ Volume scattering strength
$(\mathrm{dB})$; and RS = "Receive Sensitivity" expresses the relationship between pressure at the transducer face and the measured signal strength.

The signal strength decreases with the range due to geometric spreading and absorption. The absorption coefficient of water is a function of sound frequency, salinity, temperature, and pressure. Pressure does not have a significant effect on the absorption coefficient for shallow water systems (depth $\leq 20 \mathrm{~m}$; Alvarez and Jones 2002). The absorption coefficients $(\alpha)$ for water used in the signal strength calculations for the ADV for different temperature and salinity values were estimated by the approach of Shulkin and Marsh (1962):

$$
\begin{aligned}
\alpha= & \left(\frac{\mathrm{SA} f_{t} f^{2}}{f_{\mathrm{T}}^{2}+f^{2}}+\frac{3.38 \times 10^{-6} f^{2}}{21.9 \times 10^{6-[1520 / T+273]}}\right) \\
& \times\left(1-6.54 \times 10^{-4} \mathrm{P}\right)
\end{aligned}
$$

where $\alpha=$ absorption coefficient, in nepers per meter; $S=$ salinity, in parts per thousand; $P=$ water pressure, in atmospheres; $f=$ the acoustic frequency, in kilocycles per second ( $f=10,000$ here); $T=$ water temperature, in ${ }^{\circ} \mathrm{C} ; A=$ constant for the $\mathrm{MgSO}_{4}$ ionic relaxation process in 


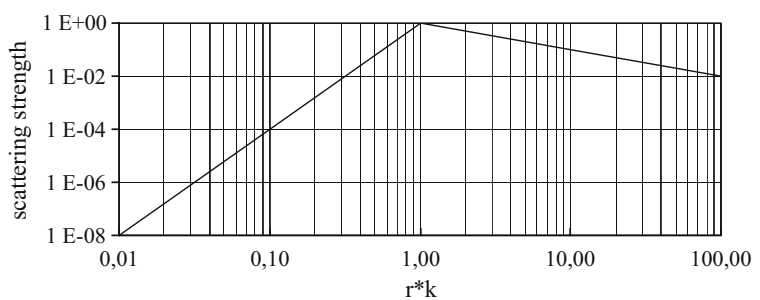

Fig. 3 Variation of scattering strength of the equipment in terms of particle size (Sontek 1998). Here, $r$ is the radius of the particle, and $k$ is the acoustic wave number $(2 \pi / \lambda)$

sea water $\left(A=2.34 \times 10^{-6}\right)$; and $f_{\mathrm{T}}=$ temperature dependent relaxation frequency in $\mathrm{kHz}$ at atmospheric pressure as:

$$
f_{\mathrm{T}}=21.9 \times 10^{\left(6-\frac{1520}{T+273}\right)}
$$

The pressure term is insignificant for depths less than $20 \mathrm{~m}$, and the salinity term is neglected for fresh water, resulting in the following

$\alpha=8.687 \times \frac{3.38 \times 10^{-6} f^{2}}{21.9 \times 10^{6-[1520 / T+273]}}$

where, 8.687 is the conversion factor from nepers to decibels.

Parameters affecting the relationship between the signal strength readings (recorded by ADV) and SSC (measured by turbidity sensor) were investigated in this study. Soil samples were collected from the rivers, and analyzed as described below to define particle size distribution for each river. The particle size distributions of the suspended sediments are presumed comparable to those of the bed material, although some differences would exist due to the armoring process and flocculation. The collected bed material was dried at room temperature, then lightly granulated to perform sieve analysis. Sieve analysis was applied to sediments finer than $2 \mathrm{~mm}$ to find the distribution of sediment particles suspended in water. Sieve analysis was conducted using sieve numbers $8,16,30,50,100$, and 200 as specified in the American Society for Testing and Materials Standards (ASTM) for the range of soils from $2 \mathrm{~mm}$ to $0.075 \mathrm{~mm}$. After the sieve analysis, hydrometer analysis was applied to 50 grams of the soil sample finer than $0.075 \mathrm{~mm}$ (sieve number 200) to determine the distribution of the finer sediment particles. This fraction was placed in the shaker, and mixed 30 min with $200 \mathrm{ml}$ distilled water and $20 \mathrm{ml} \mathrm{25 \%}$ sodium hexametaphosphate solution. Clean water $(800 \mathrm{ml})$ was added and the mixture was placed into the constant temperature pool and hydrometer analysis was performed for 48 hours as given in the ASTM D 422.

The soil granulometry for each measurement site is shown in Fig. 3. The particle distribution properties of the sampled riverbed soils are given in Table 1. In this table, the coefficient of gradation, $C_{g}$, is the measure of the shape of the particle size curve, and the distribution is well graded if $C_{g}$ is between 1 and 3 . The coefficient of gradation is defined by Eq. 5:

$C_{\mathrm{g}}=\left(D_{30}\right)^{2} /\left(D_{60} \times D_{10}\right)$

where $D_{10}, D_{30}$, and $D_{60}$ denote the value of particle diameters for percentage of cumulative distribution of 10,30 , and $60 \%$ respectively.

The sensitivity of acoustic instruments varies with particle size. Each acoustic frequency has a particle size that maximizes sensitivity, and, likewise, a minimum detectable particle radius. Theoretically, the highest scattering strength is obtained when $r \times k=1$, where $r$ is the radius of the particle, and $k$ is the acoustic wave number $(2 \pi / \lambda)$. For the instrument used in this study, the corresponding acoustic wavelength $\lambda$ is $0.157 \mathrm{~mm}$,

Table 1 Particle size distribution of the rivers and streams where data were collected

\begin{tabular}{|c|c|c|c|c|c|c|}
\hline Station & Sand (\%) & Silt (\%) & Clay $(\%)$ & $\%$ Finer than $d_{\min }$ & $d_{50}(\mathrm{~mm})$ & Gradation coefficient $\left(C_{g}\right)$ \\
\hline Sasal & 23.39 & 45.80 & 30.81 & 12 & 0.025 & 0.34 \\
\hline Tahtali & 30.93 & 27.41 & 41.66 & 28 & 0.015 & 0.25 \\
\hline Gediz & 49.78 & 20.78 & 29.44 & 18 & 0.075 & 1.00 \\
\hline Gulbahce & 96.54 & 1.43 & 2.03 & 1 & 0.55 & 0.88 \\
\hline
\end{tabular}

$d_{\text {min }}$ refers to minimum particle size detectable by $\mathrm{ADV}, d_{50}$ refers to mean diameter of the sediment sample and $C_{g}$ is the gradation coefficient of the particle size distribution 
Fig. 4 Particle granulometry of the soils sampled in the measurement sites. Arrow (1) shows the best sensitivity particle size $(0.025 \mathrm{~mm})$ and arrow $(2)$ shows minimum particle size to be detected (0.001 $\mathrm{mm})$ by the ADV used in this study

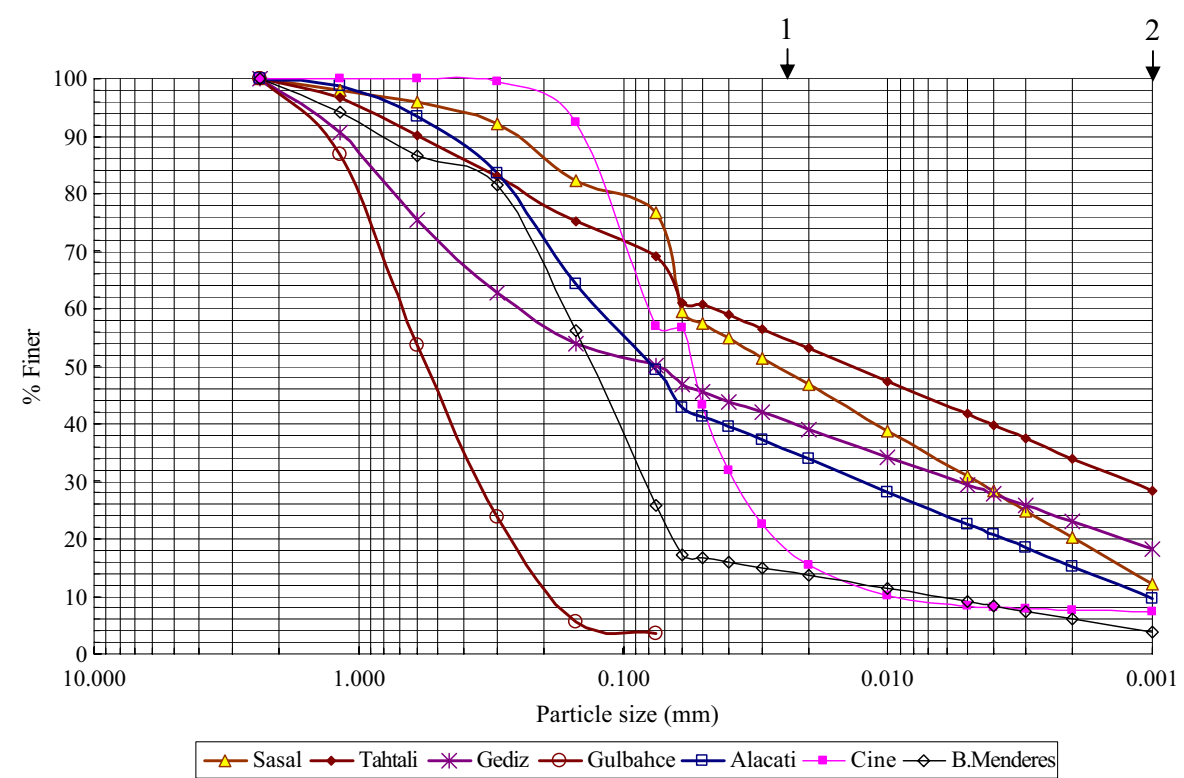

and peak sensitivity occurs for particle radius of $0.025 \mathrm{~mm}$, meaning that the ADV would give best results for SNR in streams having the highest percentage of soils close to this radius. The scattering strength depends on particle size as described by a simple model shown in Fig. 4 (Sontek 1998). Scattering strength decreases rapidly for particles smaller than, in this case, $0.025 \mathrm{~mm}$. Typical minimum particle size was detected as $0.001 \mathrm{~mm}$ for the ADV used in this study.

\section{Field and laboratory applications}

Field measurements obtained with the $10 \mathrm{MHz}$ ADV system and turbidity meter were compared for each of the chosen locations to investigate the relationship between SNR and SSC data. Table 2 shows the flow and water characteristics reported by the water quality meter at each measurement location and instance. The relationship between SNR and SSC values was primarily assessed using

Table 2 The water characteristics for each measurement site and location

\begin{tabular}{|c|c|c|c|c|c|c|c|c|c|}
\hline No & Station & Date & Depth $(\mathrm{m})$ & $T_{\mathrm{w}}\left({ }^{\circ} \mathrm{C}\right)$ & DO $(\mathrm{mg} / \mathrm{l})$ & $\mathrm{EC}(\mathrm{S} / \mathrm{m})$ & $\mathrm{pH}$ & $S(\mathrm{mg} / \mathrm{l})$ & Water condition \\
\hline 1 & Sasal & 20.10 .2006 & 0.3 & 15.7 & 10.6 & 0.05 & 8.1 & 0.2 & Clear \\
\hline 2 & Sasal & 04.11.2006 & 0.8 & 12.5 & 9.4 & 0.04 & 8.2 & 0.1 & Flood \\
\hline 3 & Sasal & 26.11.2006 & 0.7 & 13.5 & 9.6 & 0.05 & 8.3 & 0.2 & Clear \\
\hline 4 & Tahtali & 04.11 .2006 & 0.6 & 12.7 & 9.3 & 0.04 & 8.2 & 0.2 & Flood \\
\hline 5 & Tahtali & 26.11.2006 & 0.4 & 15.1 & 15.0 & 0.05 & 7.9 & 0.2 & Clear \\
\hline 6 & Tahtali & 28.12.2006 & 0.8 & 3.9 & 14.3 & 0.07 & 8.3 & 0.3 & Clear \\
\hline 7 & Gediz & 16.12 .2006 & 0.8 & 10.9 & 3.1 & 0.10 & 7.7 & 0.6 & Muddy \\
\hline 8 & Gediz & 23.12.2006 & 0.8 & 10.2 & 0.4 & 0.10 & 7.5 & 0.6 & Muddy \\
\hline 9 & Gulbahce & 01.11.2006 & 0.2 & 17.3 & 5.1 & 0.03 & 7.2 & 0.1 & Clear \\
\hline 10 & Gulbahce & 31.01 .2007 & 0.2 & 11.6 & 5.6 & 0.03 & 7.3 & 0.1 & Clear \\
\hline 11 & Alacati & 31.01.2007 & 0.2 & 8.6 & 12.4 & 0.05 & 8.5 & 29.0 & Muddy \\
\hline 12 & B. Mend. & 06.02.2007 & 0.3 & 9.2 & 1.5 & 0.20 & 7.3 & 0.8 & Flood \\
\hline 13 & Cine & 06.02 .2007 & 0.2 & 7.7 & 1.6 & 0.05 & 7.8 & 0.2 & Muddy \\
\hline
\end{tabular}

Depth corresponds to the mean depth of the cross section

$T_{\mathrm{w}}$ Water temperature, $D O$ dissolved oxygen, $E C$ conductivity, $S$ salinity 
least square analysis. The best fit was observed in Sasal Stream on $20.10 .2006\left(R^{2}=0.9\right.$; Fig. 5). The predicted SSC is given by the following formula:

(Estimated) $\mathrm{SSC}=1.49 \times \mathrm{SNR}-13.5$

Similarly in the Tahtali stream, SNR measurements made using the ADV followed the fluctuations in the sediment concentration introduced intentionally by the authors well. As can be seen in Fig. 6, SNR measurements followed closely the turbidity peaks observed in the river. This would be expected since Tahtali and Sasal Streams have the highest amount of suspended particles falling into the best sensitivity range of ADV, explaining the strong correlation between the datasets. In the Gediz and Gülbahçe streams, $R^{2}$ values relating SNR and SSC were 0.8 and 0.7 , respectively.

The effect of temperature and particle size distribution on prediction of SSC was investigated further via multivariate analysis. All of the data measured in the Tahtali, Sasal, Gülbahçe, and Gediz streams on the given dates (see Table 2) were used in the analysis. Multivariate analysis was carried out on a data matrix of five variables including SSC, SNR, dimensionless mean sediment diameter $\left(\frac{d_{50}}{d_{50 b}}\right)$, coefficient of gradation $\left(C_{g}\right)$, and dimensionless absorption coefficient $\left(\frac{\alpha}{\alpha_{c}}\right)$. Here, $d_{50 b}$ is the particle diameter corresponding to predicted maximum sensitivity for the $\operatorname{ADV}\left(d_{50 b}=0.025 \mathrm{~mm}\right.$ here $), \alpha_{c}$ is

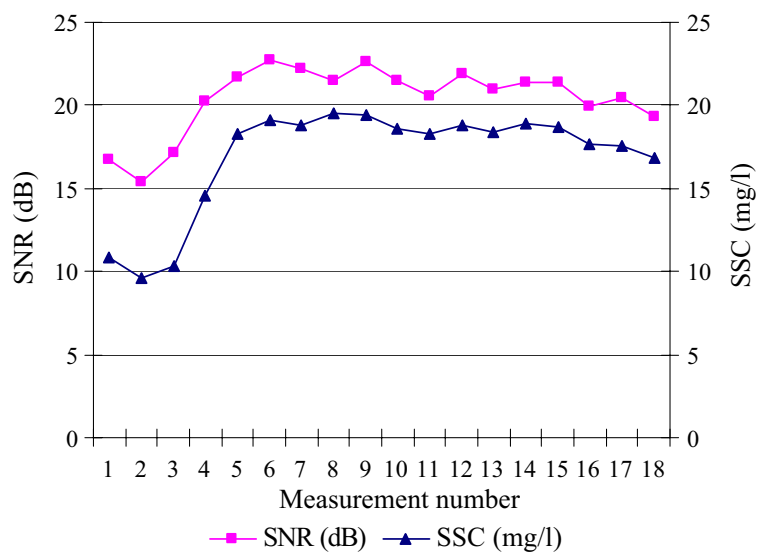

Fig. $5 \mathrm{ADV}$ and WQC measurements of Sasal Stream $\left(R^{2}=0.9\right)$

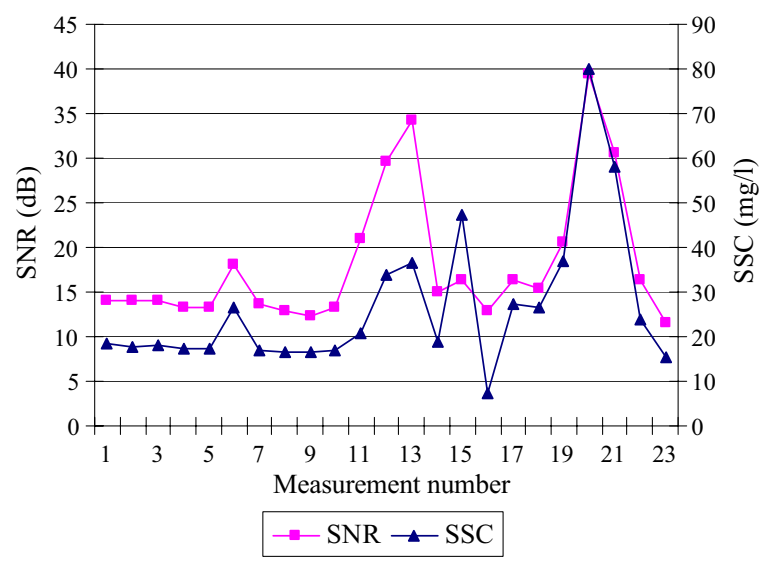

Fig. $6 \mathrm{ADV}$ and WQC measurements of Tahtali Stream $\left(R^{2}=0.7\right)$

the absorption coefficient for the calibration temperature $\left(4^{\circ} \mathrm{C}\right)$ calculated using Eq 4. Simca-P 10.5 software (Umetrics 2003) was applied for partial least-squares (PLS) modeling. PLS analysis extracts the degree of explanation of the dependent $Y$ variable (SSC measurements) for each independent $X$ variable (SNR readings, dimensionless mean sediment diameter, coefficient of gradation, and temperature, represented by absorption coefficient). Results of the PLS analysis indicated the importance level of the variables (VIP; Fig. 7) summarizing the overall contribution of each independent $X$ variable to the PLS model, weighted according to the variation of dependent $Y$ variable (Umetrics 2003).

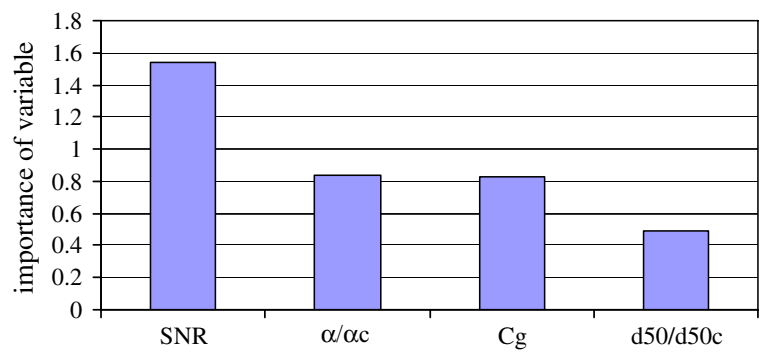

Fig. 7 Importance of variables used in the multivariate analysis. Here, SNR denotes signal-to-noise ratio, $\frac{d_{50}}{d_{50 b}}$ is the dimensionless mean sediment diameter, $C_{g}$ is the coefficient of gradation and $\frac{\alpha}{\alpha_{c}}$ is the dimensionless absorption coefficient 
Since both dimensionless mean sediment diameter $\left(\frac{d_{50}}{d_{50 b}}\right)$, and coefficient of gradation $\left(C_{g}\right)$, are soil properties, these two parameters were combined by multiplication and PLS analysis was conducted using a data matrix of four variables (SSC, SNR, $\left.\frac{d_{50}}{d_{50 b}} \times C_{g}, \frac{\alpha}{\alpha_{c}}\right)$.

A new PLS model was utilized based on these four parameters. The following equation gave the relationship between these parameters:

$$
\begin{aligned}
\mathrm{SSC}= & -13.8+0.8 \times \mathrm{SNR}+21.04 \\
& \times \frac{\alpha}{\alpha_{c}}+4.52 \frac{d_{50}}{d_{50 b}} \times C_{g}
\end{aligned}
$$

Simca-P 10.5 estimates the predictive ability of the model defined by predicted residual sum of squares $\left(Q^{2}\right)$ by cross-validation. The data are divided into seven parts and a model is built on (6/7)th of the data, where the omitted data are predicted from the new model. This is repeated with each (1/7)th of the data until all the data have been predicted (Umetrics 2003). The predicted data are then compared with the original data and the sum of squared errors calculated for the whole dataset. $Q^{2}$ was calculated as 0.90 for the model. Figure 8 gives the comparison of observed SSC values and the SSC values predicted by the model. The computed MAE [Mean Absolute Error] and MRE [Mean Relative Error] for Eq. 7 were $1.88 \mathrm{mg} / \mathrm{L}$ and $10 \%$, respectively.

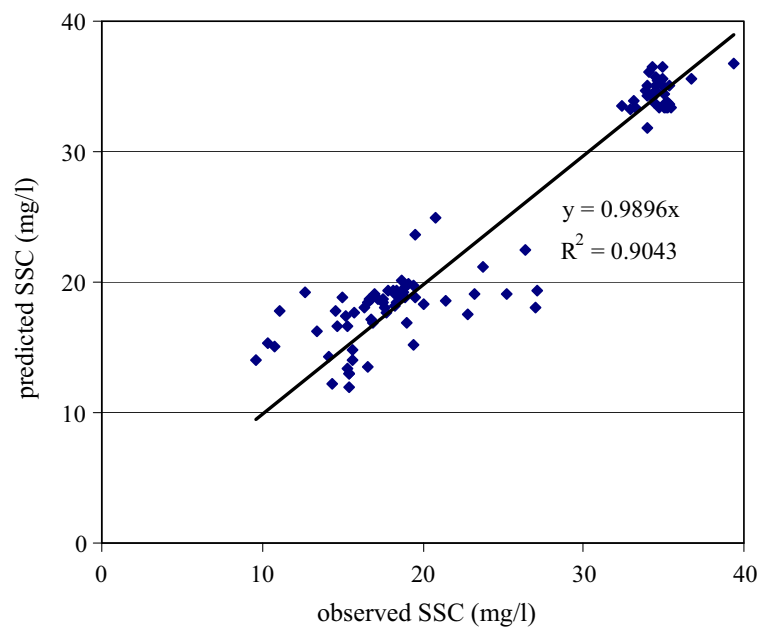

Fig. 8 The comparison of observed SSC values and the SSC values predicted by the model

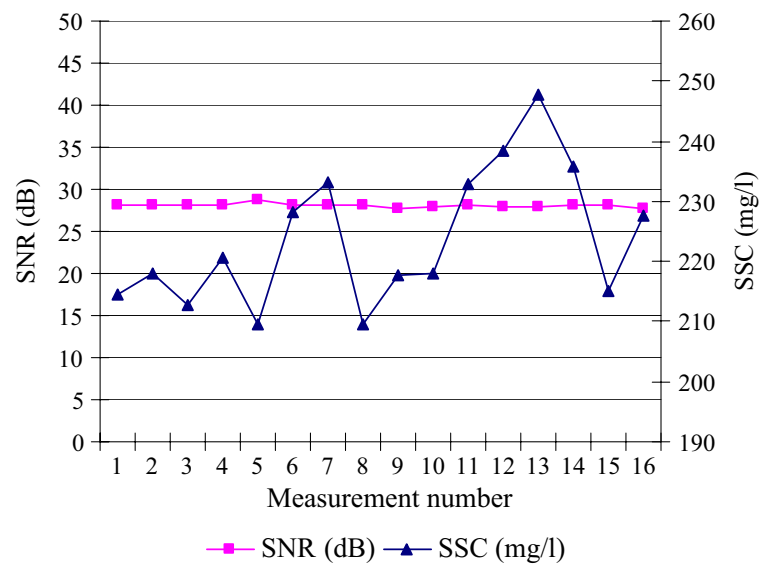

Fig. 9 ADV and WQC measurements of Sasal River in flood condition

\section{Flood effect}

Measurements were made during and after rain events to investigate the performance of the ADV for predicting the suspended sediment concentration. The ADV failed to predict SSC in highly turbid conditions ( $\mathrm{SSC}>200 \mathrm{mg} / \mathrm{l})$. As can be seen in Figs. 9 and 10, for high SSC values (SSC $\approx$ $230 \mathrm{mg} / \mathrm{l}$ ), the ADV could not resolve the changes in SSC, and SNR values remained constant at $28 \mathrm{~dB}$ in Tahtali and Sasal Streams, which are located in the same basin. In the Cine Stream and the B. Menderes River, which are also located in the same basin, similarly SNR values remained

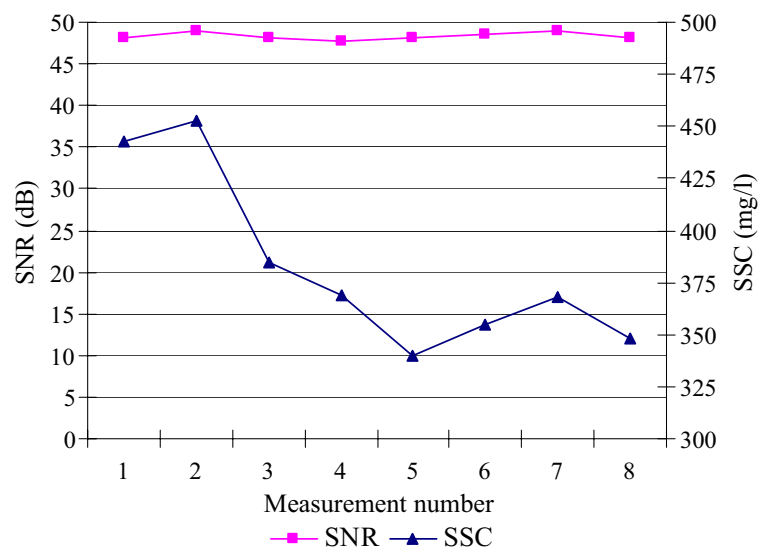

Fig. $10 \mathrm{ADV}$ and WQC measurements of Cine Stream in flood condition 
constant at $48 \mathrm{~dB}$ during flood conditions $(\mathrm{SSC} \approx$ $400 \mathrm{mg} / \mathrm{l}$ ). Maximum SNR readings obtained from the ADV depend on the particle size distribution. Soils in the Tahtali and Sasal Streams have finer sediments and higher percentage of fine particles smaller than the minimum detectable size, as compared to the Cine and B. Menderes sites. The measurements showed clearly that ADV readings are not dependable for SSC prediction in highly turbid water conditions.

\section{Conclusions}

A methodology was developed and applied to allow the use of an acoustic Doppler velocimeter (ADV) for estimation of SSC in different streams and rivers located in the Aegean region of Turkey where the mean diameter of the sediment samples varied between 0.015 to $0.55 \mathrm{~mm}$. Simultaneous measurements were made using a water quality meter and an ADV at each site. SNR reported by the ADV was compared with measured SSC data. The correlation of the SNR and SSC data was investigated through statistical methods.

Measurements showed that the ADV can be used to estimate SSC in low-turbid (SSC < $200 \mathrm{mg} / \mathrm{l}$ ) water systems. When SSC values were plotted against SNR values, the regression coefficients varied between 0.7 and 0.9 for four streams. For any acoustic sensor relying on reflected sound for measurements, there is a particle size that will result in maximum instrument sensitivity. As the fraction of suspended particles near this particle size ( $d=0.025 \mathrm{~mm}$ in this study) increased, the regression coefficient of SNR and SSC values approached unity.

Variations in temperature affecting the absorption coefficient of water and thus the signal strength reported by the ADV were also investigated. Multivariate analysis indicated that reported SSC values depend on at least three parameters: water temperature, mean diameter of the soil, and shape of the particle size distribution curve. A model consisting of these parameters predicted SSC values in different streams having different soil properties and water temperatures with high predictive ability $\left(Q^{2}=0.90\right)$, calculated from the sum of squared errors for the whole dataset.

The predictive equation developed in this study has general applicability since it is not site-specific. It includes the effects of particle size distribution and water temperature in the prediction of SSC by acoustic methods. This methodology does not consider either the effect of organic material or the effect of sediment density.

ADV predictions of SSC were not possible when turbidity exceeded a limit concentration (SSC > $400 \mathrm{mg} / \mathrm{l}$ ) determined by the sediment size distribution for the measurement site. Monitoring water and sediment flow by ADVs has a number of advantages over other instruments; however, providing after appropriate calibration, three-dimensional flow velocity, temperature, and suspended sediment concentration time series with one instrument.

Acknowledgements Equipment used in this study is partly funded by a research grant from the European Commission, via project No: 028292 (RESTRAT).

\section{References}

Alvarez, L. G., \& Jones, S. E. (2002). Factors influencing suspended sediment flux in the upper Gulf of California. Coastal and Shelf Science, 54, 747-759. doi:10.1006/ecss.2001.0873.

Carbo, R., \& Molero A. C. (2000). The effect of temperature on sound wave absorption in a sediment layer. Acoustical Society of America, 108(4), 1545-1547.

Creed, E. L., Pence, A. M., \& Rankin, K. L. (2001). Intercomparison of turbidity and sediment concentration measurements from an ADP, an OBS-3, and a LISST. Retrieved November 11, 2006 from http://marine. rutgers.edu/mrs/newark/Assets/215_OCEANS_2001_ paper.pdf.

Elci, S. (2008). Estimation of suspended sediment concentration in stratified lakes by acoustic methods in Encyclopedia of Lakes and Reservoirs, Geography, Geology. In R. W. Fairbridge \& R. W. Herschy (Eds.), published by Springer, accepted, in press.

Gartner, J. W. (2002). Estimation of suspended solids concentrations based on acoustic backscatter intensity: Theoretical background. Turbidity and other sediment surrogates workshop. Reno, NV.

Hoitink, A., \& Hoekstra, P. (2005). Observations of suspended sediment from ADCP and OBS measurements in a mud-dominated environment. Coastal Engineering, 52(2), 103-118. 
Hosseini, S. A., Shamsai, A., \& Ataie-Astiani, B. (2005). Synchronous measurements of the velocity and concentration in low density turbidity currents using an Acoustic Doppler Velocimeter. Flow Measurement and Instrumentation, 17, 59-68. doi:10.1016/j. flowmeasinst.2005.05.002.

Kostaschuk, R. A., Best, J., Villard, P. V., Peakall, J., \& Franklin, M. (2004). Measuring flow velocity and sediment transport with an acoustic Doppler current profiler. Geomorphology, 68, 25-37. doi:10.1016/ j.geomorph.2004.07.012.

Rennie, C. D., Millar, R. G., \& Church, M. A. (2002). Measurement of bed load velocity using an acoustic Doppler current profiler. Journal of Hydraulic En- gineering, 128, 473-483. doi:10.1061/(ASCE)07339429(2002)128:5(473).

Shulkin, M., \& Marsh, H. W. (1962). Sound absorption in sea water. The Journal of the Acoustical Society of America, 34(6), 864-865. doi:10.1121/1.1918213.

SonTek Technical Notes (1998). Doppler current metersusing signal strength to monitor suspended sediment concentration. San Diego, CA, USA: SonTek.

Umetrics (2003) Statistical notes in Simca-P 10.5 help menu. Umetrics AB.

Work, P. A. (2008). Nearshore directional wave measurements by surface-following buoy and acoustic Doppler current profiler. Ocean Engineering, 35, 727-737. Elsevier. doi:10.1016/j.physletb.2003.10.071. 